\title{
Regulation of Food Intake and Body Weight by Insulin
}

\author{
D. Porte, Jr. and S. C. Woods \\ Departments of Medicine and Psychology, University of Washington School of Medicine, \\ and the Veterans Administration Medical Center, Seattle, Washington, USA
}

Summary. A feedback system for the regulation of food intake and body weight, consisting of two elements is proposed. One is related to the quantitiy and quality of the food ingested. It consists of neural afferents, psychosocial conditioning factors, and peptide signals from the gastrointestinal tract released by specific nutrient intake. The other is also sensitive to nutrient intake, but importantly modulated by relative adiposity. We present evidence to suggest that insulin serves as the key feedback signal to the central nervous system to serve this second function (body adiposity signal). Insulin has been found in cerebrospinal fluid where its concentration is increased by systemic infusions of glucose or insulin and is proportional to its concentration in plasma. When insulin (10 and $100 \mu \mathrm{U} / \mathrm{kg} /$ day) is infused into the lateral cerebral ventricles of free feeding baboons a dose dependent suppression of food intake and body weight is found. Intravenous infusion of $25 \%$ and $50 \%$ of total calories as glucose elevates endogenous insulin concentrations and suppresses food intake. These findings suggest that the amount of insulin secreted per day and more modulates food intake to maintain a constant body weight.

Key words: Insulin, food intake, feeding, CNS, body weight, adiposity

Factors influencing the regulation of food intake may be divided into two categories. The first includes stimuli regulated independently of body fat stores to change meal size. They include psychosocial factors, stimuli which predict the presence of food, stimuli originating in the food itself (tastes, odours, etc.), stimuli associated with chewing and processing food, and stimuli elicited by the physicochemical properties of the food. These usually suppress food intake and are therefore satiety factors [1] but some are clearly stimulatory and produce hunger $[2,3]$. These signals are independent of body fat stores.

The second category of controlling factors are regulated by the size of the adipose mass, although they may be stimulated or suppressed by the environment or the meal. They provide a mechanism for coupling weight regulation to meal feeding. It is the integration of the signal(s) sensitive to fat mass with the adiposity independent signals which determines food intake, energy expenditure and ultimately, body weight. In this paper, we shall consider evidence that insulin is a peptide signal sensitive to the amount of stored fat which also regulates food intake and subsequently, body adiposity. In a second paper [4], we shall discuss the role of other meal-related peptides. A schematic summary of the interaction of these influences is presented in Figure 1 [5].

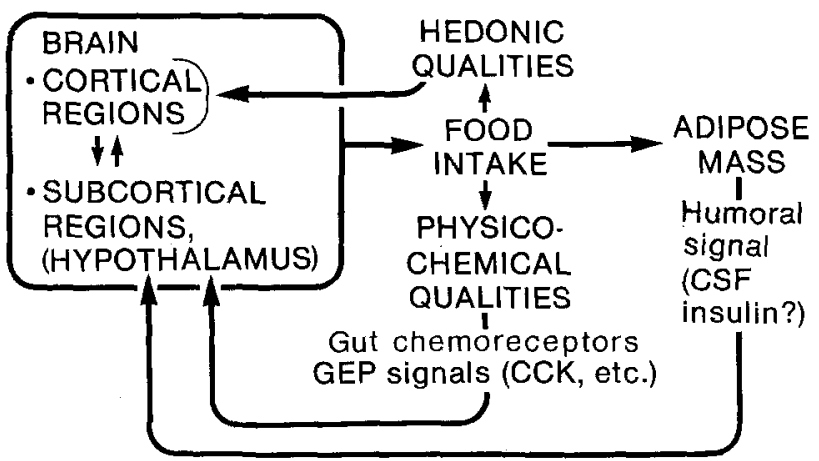

Fig. 1. A schematic representation of the interaction between central factors for the regulation of food intake and body weight. Note the postulated role for insulin as the message which informs central integrating mechanisms of the relative size of the adipose mass 


\section{Regulation of Body Adiposity}

Gasnier and A. Mayer [6] were among the first to note that animals (rabbits, in their experiments) subjected to a considerable range of energy expenditure (exercise) maintained a constant body weight by varying their food intake. This relationship was most apparent for energy flux calculated over intervals of more than one meal or one day. The best relationship occurred when the data were summed over one-week intervals, suggesting that the feedback mechanism between adiposity and food intake was not rapid. Others have obtained similar findings in other species [7]. This relationship between energy expenditure and food intake is strong evidence for some type of regulatory feedback system.

If one challenges the system by restricting food or force feeding, compensatory readjustment of food intake occur. Rats [8] or humans [9] which are overfed and made relatively obese undereat and lose weight when the overfeeding is stopped. When underfed to the point of weight loss, they overeat and regain their pre-experimental weight when given the opportunity. Thus animals and people resist imposed attempts to alter their body adiposity, and they generally do this by altering food intake. This is the predominant problem with human obesity. The obese individual who diets almost always overeats and regains the previous (obese) weight when inducements and/or enthusiasm wane.

This does not imply that animals do not have strategies other than changing food intake to regulate adiposity. Models have been developed in which body adiposity is altered even though food intake is held constant. In these instances, other strategies including changes of exercise and apparent shifts of metabolic efficiency must have occurred [10].

A circulating adiposity signal has been suggested by studies of parabiotic animals $[11,12]$. A parabiotic genetically obese animal remains obese, but the control lean animal of the pair undereats and frequently dies. The nature of this circulating signal or signals is the subject of this paper.

\section{Insulin and Adiposity}

There is an impressive relationship between the degree of adiposity and the level of insulin in the plasma $[13,14]$, with insulin secretion proportional to the degree of adiposity. This has been shown for man, other primates, and a variety of other species [14]. Within species this relationship also exists for individuals. When animals or humans change their weight, insulin secretion changes simultaneously [9,
$14,15]$ although it is uncertain which variable, if either, is causal in this relationship.

We have postulated that insulin levels might provide the signal which controls food intake to maintain a constant body weight $[16,17]$. Overeating or weight gain would be accompanied by an increase in plasma insulin concentrations which feedback to curb appetite and ultimately reduce weight. One problem with this hypothesis is that insulin secretion varies with the activity of the individual, including feeding, exercise, arousal, stress, emotions, etc. Although mean insulin secretion during a day correlates well with adiposity, moment-to-moment insulin levels in a normal animal reflect other metabolic needs in addition. Further potential problems with insulin being considered as an adiposity signal were that the hormone is a peptide, that it may not cross the bloodbrain barrier and that brain cells do not respond to insulin by accelerating glucose uptake. Recent observations suggest that these may no longer be considered serious objections.

\section{Insulin and Insulin Effects in the Central Nervous System}

To investigate the CNS mechanisms for reflexive insulin secretion $[18,19]$, we obtained serial samples of cerebrospinal fluid (CSF) from the cisterna magnum of anaesthetized dogs. Immunoreactive insulin (IRI) was detectable in the CSF [20] and concentrations rose after intravenous administration of either glucose or insulin [21]. However, CSF insulin did not change nearly as rapidly as plasma insulin. The rapid fluctuations of plasma insulin were damped to a great degree in CSF but CSF insulin was a slow integral over time of the concentration in the plasma. Insulin thus had access to brain tissue and its dynamics fulfilled the criteria for a signal which would not fluctuate rapidly, and would represent body adiposity.

Other workers have also reported the presence of insulin within the CSF of various species. The CSF of humans contains insulin in small amounts when measured by bioassay [22] or radioimmunoassay [23]. Obese humans have elevated CSF insulin concentrations compared to lean controls [24], and levels decline with fasting. These data support a role for CSF insulin as an adiposity signal.

Binding sites characteristic of insulin receptors are found in regions of the CNS influential in feeding $[25,26]$. Furthermore, insulin injected into the CSF leads to stimulation of vagal nerves to the endocrine pancreas $[20,27-29]$ and when applied iontophoretically to specific hypothalamic neurons alters their electrical activity $[30,31]$. Thus despite the absence 
C
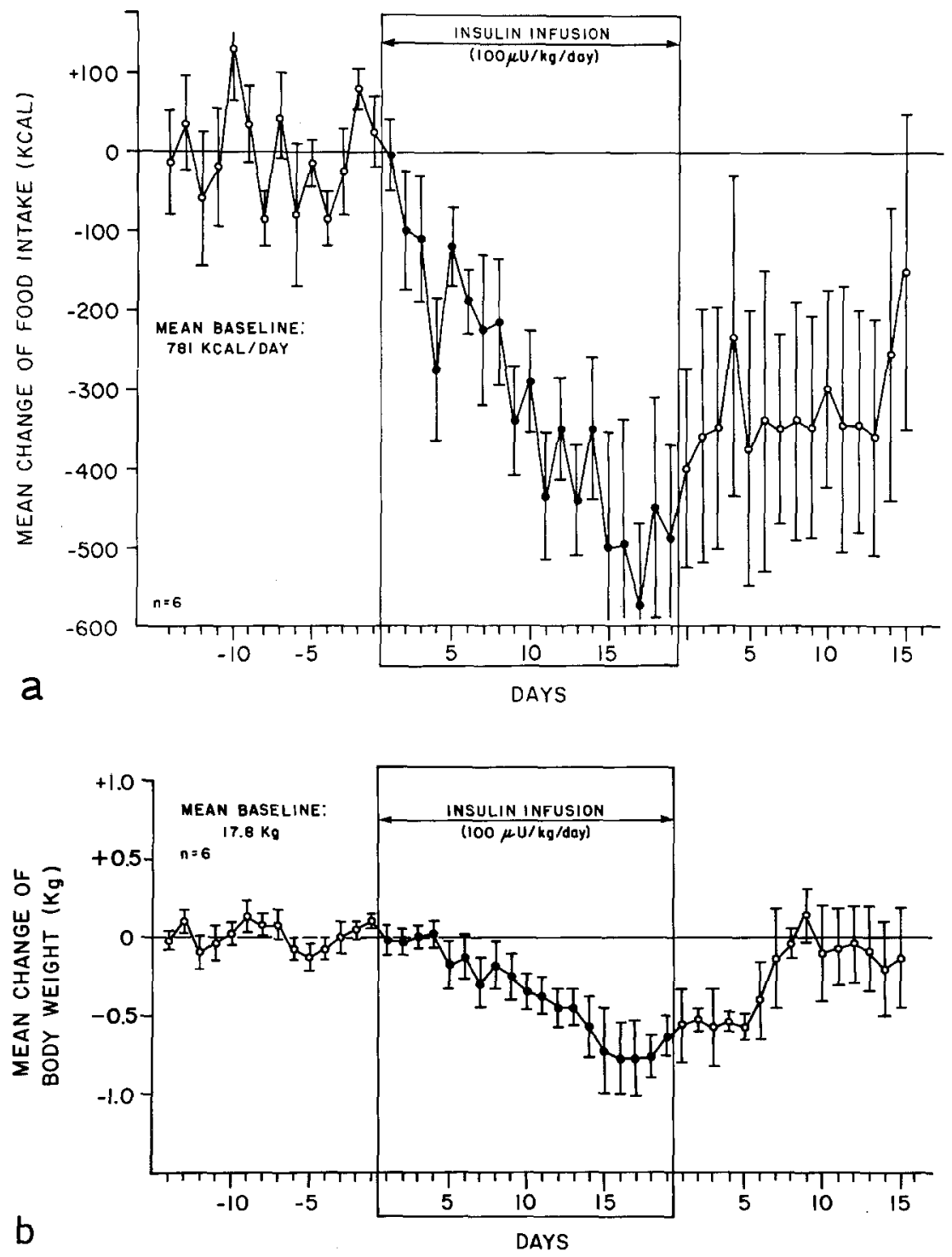

Fig. 2a. The effect of intraventricular insulin $(100 \mu \mathrm{U} / \mathrm{kg} /$ day $)$ on food intake in free feeding baboons (35). Note the progressive effect of a constant infusion and the delayed recovery time. $\mathbf{b}$ The effect of intraventicular insulin $(100 \mu \mathrm{U} / \mathrm{kg} /$ day $)$ on body weight. Same six baboons as $2 \mathrm{~A}$. Note that body weight recovers sooner than food intake

of stimulated glucose transport insulin does have specific binding sites and effects in the CNS.

\section{Increased CSF Insulin Decreases Food Intake and Body Weight}

We have further examined the role of CSF insulin in regulation of food intake in unanaesthetized baboons. Baboons, being large and easily catheterized, provide adequate blood and CSF for analysis and are phyllogenetically close to humans. Male baboons were adapted to living in standard primate restraining chairs in sound-attenuated chambers. They were fed a nutritionally complete liquid diet (Ensure, Ross Labs) beginning every morning at
$0830 \mathrm{~h}$. At $1530 \mathrm{~h}$ the food eaten was measured and replaced with water which was then available until $0830 \mathrm{~h}$ the next morning. The baboons typically consume a large meal when the food is first made available. They then eat smaller meals throughout their feeding day. They readily accept the diet and do not lose weight as a result of the conditions of the housing or feeding schedule.

The effect of exogenous insulin on food intake was assessed by infusion of insulin through catheters inserted in the lateral cerebral ventricles [33].

Infusion of a sterile salt solution (synthetic monkey CSF, [34] (1.3 ml/day) had no effect upon food intake or body weight over prolonged intervals. After a 10 to 14-day baseline period, insulin was added to the infusate to give rates of 1,10 or $100 \mu \mathrm{U} / \mathrm{kg} /$ day. 
The smallest dose had no effect but the two larger doses of infused insulin caused a significant reduction of food intake and body weight, with the largest dose causing the largest effect. Figure 2 shows the body weight (taken daily at $0825 \mathrm{~h}$ ) and daily feeding responses during the highest infusion rate. No change in plasma insulin or glucose levels was observed during any of these infusions.

To control for possible non-specific (toxic) effects of an infused peptide upon food intake, we infused glucagon into the CSF of some animals at the same molar dose as the highest effective dose of insulin. Glucagon had no consistent effect upon food intake or body weight. Unfortunately, we could not obtain samples of CSF by exerting negative pressure on the cannula and could not monitor the levels of insulin in the CSF. Since infused insulin did not elicit abnormal behaviour or change the pattern of feeding, we con-

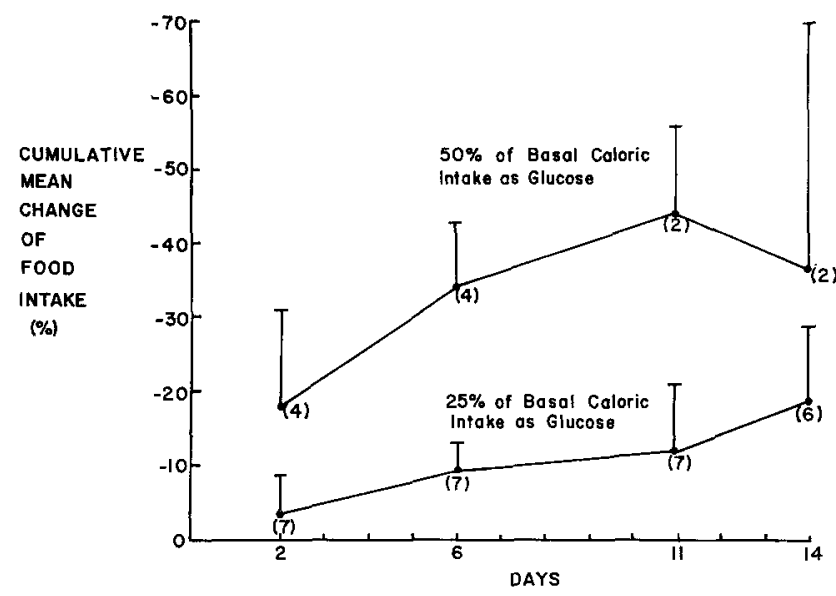

Fig. 3. Cumulative food intake suppression by glucose infusions at $25 \%$ or $50 \%$ of baseline caloric intake in free feeding baboons cluded that the insulin caused a specific reduction of food intake [35]. Others have reported a decrease of single meal feeding after injection of insulin centrally $[36,37]$ and increased feeding after centrally administered insulin antibodies [38].

More recent experiments have concentrated on changing endogenous peripheral insulin levels rather than administering exogenous insulin into the brain [39]. Baboons were again adapted to the housing conditions and liquid diet regimen as described above. Intravenous catheters enabled infusion and withdrawal of blood samples. Baseline food intake was determined for a 10 to 14-day period during which weight was stable. Glucose was infused intravenously at a rate calculated to deliver 25 or $50 \%$ of each animal's mean daily caloric food intake over $24 \mathrm{~h}$. This caused a dose dependent reduction of food intake over a 2-week interval (Fig. 3). There was considerable variability between monkeys in terms of the magnitude and the onset of the suppression (Fig. $4 \mathrm{a}$ and $\mathrm{b}$ ), and a reduction of food intake did not occur for several days.

Plasma samples were taken on alternate mornings before food. Additionally on one day during each period plasma samples were taken every $20 \mathrm{~min}$ throughout the time that food was available. Basal IRI values averaged $61 \mu \mathrm{U} / \mathrm{ml}$ in the control period prior to infusion of $25 \%$ of daily mean caloric intake as glucose. Levels rose to $79 \mu \mathrm{U} / \mathrm{ml}$ during the first 14 days. Fifty percent of calories as glucose raised plasma insulin from a baseline of 72 to $80 \mu \mathrm{U} / \mathrm{ml}$ over the same interval. Basal glucose levels rose from 82 to $170 \mathrm{mg} / \mathrm{dl}$ and from 122 to $241 \mathrm{mg} / \mathrm{dl}$ for the $25 \%$ and $50 \%$ infusions respectively.

A significant inverse correlation was obtained between IRI output (calculated from the 20 -minute
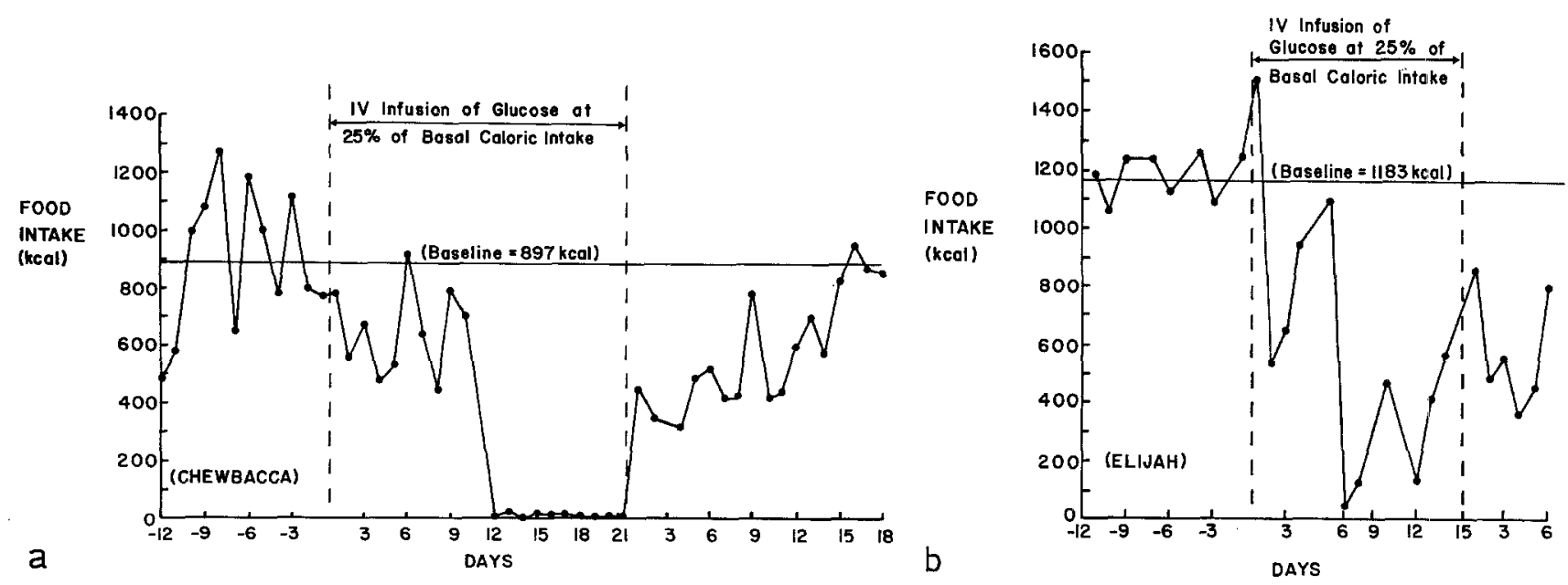

Fig. $4 \mathbf{a}$ and $\mathbf{b}$. The effect on food intake of $25 \%$ of calories infused as glucose intravenously for 2 or 3 weeks in two individual baboons. Note the variability of the food intake response 
all day samples) and food intake over the subsequent three days. A less significant correlation was also obtained between output and food intake on any of the next three days individually. This again suggests that the response to the glucose infusion to regulate food intake is delayed.

The effect of chronic glucose infusion on food intake may result from either the hyperglycaemia (J. Mayer's glucostatic theory, 40) or hyperinsulinaemia (our hypothesis). Gut factors are evidently not involved. The delay is not what is expected for the glucostatic theory and short term glucose infusions are ineffective in influencing food intake. Nevertheless we have attempted to control for the effects of the glucose level per se. Baboons were infused with glucose at $25 \%$ of their daily mean caloric intake and in addition received a small amount of insulin $(0.33 \mu \mathrm{U} / \mathrm{kg} / \mathrm{min})$. This abolished the basal hyperglycaemia (mean increase $2 \mathrm{mg} / \mathrm{dl}$, $\mathrm{n}=3$ ) during the infusion, but the decrease in food intake was similar $(-13 \%)$. This suggests that the hyperglycaemia per se is not the direct cause of the decrease in food intake.

In a similar experiment with rats, Nicolaidis and Rowland [41] found that intravenous infusion of glucose plus insulin resulted in a greater suppression of food intake than the infusion of glucose alone. If insulin is given alone, animals overeat and gain weight [42] probably as a result of hypoglycaemia [43]. In the Nicolaidis and Rowland experiments [41] and in our own experiment [39], the concomitant glucose infusion prevents hypoglycaemia and enables insulin to exert its direct effect to reduce food intake. In confirmation of this interpretation, Vanderweale, et al. [44] recently reported that the slow delivery of insulin subcutaneously via osmotic minipumps causes a decrease of food intake over a one-week period in rats.

Acknowledgements. Supported by NIH grants AM17844, Am12829, the Diabetes Research Center of the University of Washington (AM17047), the Regional Primate Center (RR00166) and the Veterans Administration.

We wish to thank our colleagues Dr. Mei Chen, Dr. Elizabeth Lotter, L. David McKay and Leslie Stein for their participation in the studies and concepts summarized here and our laboratory and secretarial staffs for their hard work and dedication $(\mathrm{H}$. Beiter, M. Vogel, K. Guest, B. O'Neill, K. Vogel, C. Holmes and A. Bartlett).

\section{References}

1. Smith GP, Gibbs J (1979) Postprandial satiety. Prog Psychobiol Physiol Psychol 8: 179-242

2. Margules DL, Moisset B, Lewis MJ, Shibuya H, Pert CB (1978) Beta-endorphin is associated with overeating in geneti- cally obese mice (ob/ob) and rats $(\mathrm{fa} / \mathrm{fa})$. Science 202: 988-991

3. Kenney NJ, McKay LD, Woods SC, Williams RH (1978) Effects of intraventricular beta-endorphin on food intake in rats. Soc Neurosci 4: 176

4. Woods SC, West DB, Stein LJ, McKay LD, Lotter EC, Kenney NJ, Porte SG, Porte DIr (1981) Peptides and the control of meal size. Diabetologia 20 [Suppl]: 305-312

5. Porte DJr, Woods SC (1980) Insulin effects on the central nervous system (CNS): evidence for a longterm control system for body weight regulation. Proc. 10th Congress of Int. Diabetes Federation, Vienna, 1979. Excerpta Medica, Amsterdam, p 64-69

6. Gasnier A, Mayer A (1939) Recherche sur la regulation de la nutrition. II. Mecanismes regulateurs de la nutrition chez le lapin domestique. Ann Physiol Physiochim Biol 15: 157-185

7. Bray G (1976) The obese patient. WB Saunders, Philadelphia

8. Cohn C, Joseph D (1962) Influence of body weight and body fat on appetite of "normal" lean and obese rats. Yale J Biol Med 34: 598-607

9. Sims EAH, Goldman RF, Gluck CM, Horton ES, Keleher DC, Rowe DW (1968) Experimental obesity in man. Trans Assoc Am Physicians 81: 153-170

10. Bernardis LL, Goldman JK (1976) Origin of endocrinemetabolic changes in the weanling rat ventromedial syndrome. J Neurosci Res 2: 91-116

11. Hervey GR (1952) The effects of lesions in the hypothalamus in parabiotic rats. J Physiol (Lond) $145: 336-352$

12. Coleman DL, Hummel KP (1969) Effects of parabiosis of normal with genetically diabetic mice. Am $J$ Physiol 217: 1298-1304

13. Bagdade JD, Bierman EL, Porte DJr (1967) The significance of basal insulin in the evaluation of the insulin response to glucose in diabetic and non-diabetic subjects. $J$ Clin Invest 46: $1549-1557$

14. Woods SC, Decke E, Vasselli JR (1974) Metabolic hormones and regulation of body weight. Psychol Rev. 81: 26-43

15. Bernstein IL, Lotter EC, Kulkosky PJ, Porte DJ, Woods SC (1975) Effect of force-feeding upon basal insulin levels of rats. Proc Soc Exp Biol Med 150: 546-548

16. Woods SC, Porte DJr (1976) Insulin and the setpoint regulation of body weight. In: Novin D, Bray GA, Wyrwichka W (eds) Hunger: Basic mechanisms and clinical implications. Raven Press, New York, p 273-280

17. Woods SC, Porte DJr (1978) The central nervous system, pancreatic hormones, feeding and obesity. Adv Metab Disord 9: 283-312

18. Woods SC, Hutton RA, Makous W (1970) Conditioned insulin secretion in the albino rat. Proc Soc Exp Biol Med 133: 964-968

19. Woods SC, Alexander KR, Porte DJr (1972) Conditioned insulin secretion and hypoglycemia following repeated injections of tolbutamide in rats. Endocrinology 90: 227-231

20. Woods SC, Porte DJr (1975) Effect of intracisternal insulin on plasma glucose and insulin in the dog. Diabetes 24: 905-909

21. Woods SC, Porte DIr (1977) Relationship between plasma and cerebrospinal fluid insulin levels of dogs. Am J Physiol 233: E 331-334

22. Mahon WA, Steinke J, McKhann GM, Mitchell ML (1962) Measurement of $I^{131}$-insulin and of insulinlike activity in cerebrospinal fluid of man. Metabolism 11: 416-420

23. Margolis RU, Altszuler N (1967) Insulin in the cerebrospinal fluid. Nature 215: 1375-1376

24. Owen OE, Reichard GAJr, Boden G, Shuman CR (1974) Comparative measurements of glucose, beta-hydroxybutyrate, acetoacetate, and insulin in blood and cerebrospinal fluid during starvation. Metabolism 23: 7-14 
25. Van Houten M, Posner BI (1981) Cellular basis of direct insulin action in the central nervous system. Diabetologia [Suppl] 20: $255-267$

26. Havrankova J, Brownstein M, Roth J (1981) Insulin and insulin receptors in rodent brain. Diabetologia 20 [Suppl]: 268-273

27. Chen M, Woods SC, Porte DJr (1975) Effect of cerebral intraventricular insulin on pancreatic insulin secretion in the dog. Diabetes 24: 910-914

28. Anderson DK, Hazelwood RL (1969) Chicken cerebrospinal fluid: normal composition and response to insulin administration. J Physiol (Lond) 202: 83-95

29. Chowers I, Lavy S, Halpern L (1966) Effect of insulin administered intracisternally on the glucose level of the blood and the cerebrospinal fluid in vagotomized dogs. Exp Neurol 14: $383-389$

30. Oomura Y, Ohta M, Ishibashi S, Kita H, Okajima T, Ono T (1978) Activity of chemosensitive neurons related to the neurophysiological mechanism of feeding. In: Bray GA (ed) Recent advances in obesity research. Newman Publishing, London, p 17-26

31. Oomura $Y$, Kita $H$ (1981) Insulin acting as a neuromodulator through the hypothalamus. Diabetologia [Suppl] 20: 290-298

32. Woods SC, Lotter EC, Vogel KW, Porte DJr (1979) A dualpurpose device for protecting brain implants of baboons. I Neuro Neurosci Meth 1: 319-322

33. Lotter EC, McKay LD, Mangiapane ML, Simpson JB, Vogel KW, Porte DJr, Woods SC (1980) Intraventricular angiotensin elicits drinking in the baboon. Proc Soc Exp Biol Med 163: $48-51$

34. Myers RD (1971) Methods of psychobiology, Vol 1. Academic Press, New York

35. Woods SC, Lotter EC, McKay LD, Porte DJr (1979) Chronic intracerebroventricular infusion of insulin reduces food intake and body weight of baboons. Nature 282: 503-505

\section{Discussion after Porte's Presentation}

Fernstrom: Can physiological increases of insulin secretion by the pancreas be seen in the CSF? For example, what happens to CSF insulin when your animals eat?

Porte: Those studies haven't been done. The studies showing the relationship between plasma and CSF insulin levels were done in anesthetized dogs. In our chronic feeding studies using the baboon, although we could always infuse into the CSF, we were never able to obtain CSF samples from the awake, freefeeding animal. Apparently such studies are possible in the goat and the sheep, but not in the baboon, at least in our hands. We're actually doing studies like you suggest now with the use of implanted Ommayan reservoirs which communicate with the 4th ventricle of the brain. To date, we know that insulin exists in the CSF of the baboon and that CSF values range from 4 to $10 \mu \mathrm{U} / \mathrm{ml}$ when basal plasma levels are 20 to $80 \mu \mathrm{U} / \mathrm{ml}$. The ratio of CSF to plasma insulin is apparently lower in the baboon than in the dog or the human.

Pardridge: Inulin is a compound of similar molecular weight as insulin. When it is infused into the plasma of sheep such that a steady state is achieved, you find a lower CSF to plasma ratio than you observe for insulin. Barring a
36. Debons AF, Krimsky I, Likuski HJ, From A, Cloutier RJ (1972) A direct action of insulin on the hypothalamic satiety center. Am J Physiol 219: 938-943

37. Panksepp J, Nance DM (1972) Insulin, glucose and hypothalamic regulation of feeding. Physiol Behav 9: 447-451

38. Strubbe JH, Mein CG (1977) Increased feeding in response to bilateral injection of insulin antibodies in the VMH. Physiol Behav 19: 309-313

39. Woods SC, Stein LJ, McKay LD (1980) Chronic intravenous (iv) infusion of glucose reduces food intake of baboons. Diabetes 29: 116A

40. Mayer J, Thomas DW (1967) Regulation of food intake and obesity. Science 156: 328-337

41. Nicolaidis S, Rowland N (1976) Metering of intravenous versus oral nutrients and regulation of energy balance. Am J Physiol 231: 661-668

42. MacKay EM, Calloway JW, Barnes RH (1940) Hyperalimentation in normal animals produced by protamine insulin. $J$ Nutr 20: 59-66

43. Lotter EC, Woods SC (1977) Injections of insulin and changes of body weight. Physiol Behav 18: 293-297

44. VanderWeele DA, Haraczkiewicz E, VanItallie TB (1979) Insulin and satiety in obese and normal-weight rats. Soc Neurosci Abstr 5: 224

Daniel Porte, Jr., M. D.

Veterans Administration Medical Center

Division of Endocrinology/Metabolism (151)

4435 Beacon Avenue South

Seattle, WA 98108

USA direct secretion of brain insulin into the CSF, the ratio you find suggests a specific transport system for insulin.

Porte: That's also what we've been thinking. That's why we're excited by the recent data on insulin receptors on the endothelial cells of the brain [25].

Havrankova: Does an increase of CSF insulin cause a decrease of CSF glucose?

Porte: Yes, we found that in dogs when we added a large amount of insulin into the CSF. There was a decrease of CSF glucose, but it was complicated by a concomitant decrease of plasma glucose. However, when we prevented the peripheral hypoglycemia by vagotomy, the recluction of CSF glucose persisted. With the smaller amounts of insulin we're giving in the feeding experiments, we have not yet been able to sample the CSF to find out what's happening to CSF glucose. My guess is that there will be little if any change since there is no change of plasma glucose or insulin levels in those studies.

Fernstrom: How do the baboons eat? Do they eat continuously or do they eat meals? 
Porte: They tend to eat a large meal right after the food is presented in the morning and then to eat smaller meals throughout the day.

Fernstrom: It seems as if you might expect a considerable lag between the start of eating in the morning and any apparent increase of CSF insulin due to the increase in the blood during the meal.

Porte: The use of the Ommayan reservoirs should enable us to answer questions like that. Hopefully, we'll have some data before long.

Nicolaidis: We have some comparable findings from experiments in which we put insulin directly into the lateral hypothalamus (J. Ann Diabet (1978) p. 153), but we have an alternative explanation or interpretation. When we infused insulin bilaterally into the tissue, not into the CSF, adjacent to the fornical columns, the rats ate less and lost weight over a 7-day period. At the end of the experiment, they were very slow to recover the lost weight, just as in your monkeys. We felt that maybe the signal for peripheral adiposity to the brain does not necessarily have to come from the periphery. Rather, we feel that there is within the brain a microcosm of the body which mimics the situation of the macrocosm of the body's adipose mass. Thus, when there is more adiposity in the periphery, there is also more fat or lipid in these particular cells of the CNS. We have some data causing us to believe that the lipid content of certain cells in the hypothalamus can vary in this manner. So, by stimulating the system with a local infusion of insulin, a lipogenic agent, we would expect a lowering of body weight by the animal, and that is what we found. So this is a completely different interpretation of the data.

Porte: Well, regardless of which interpretation is correct, we are pleased to see your confirmatory data.

Steffens: How do you explain the delay in the onset of the feeding response and in the return to baseline after the infusion is stopped?

Porte: At the moment, we simply don't know the cause of the delay. We feel that it is real since it is consistent among monkeys. Further, there is evidence from other systems of comparable lags involving insulin. In completely unrelated experiments, we find that insulin-deficient diabetics with fasting hyperglycemia have a deficiency of adipose tissue lipoprotein lipase (LPL). If you give them insulin to make them euglycemic, blood glucose levels are restored very rapidly, but adipose tissue LPL levels are not returned to normal for 2 or 3 weeks. The adipocyte evidently has an enzyme system which responds with a very long lag phase.

Steffens: Do you think the lag may be related to a different halflife of insulin in the brain?

Porte: No, we don't. We have measured the halflife of insulin in the CSF of dogs and found it to be several hours.
Although this is much longer than in the plasma, any change should be gone within 24 hours. It's more likely that some intracellular component which is regulated by insulin has a halflife, or memory if you like, which is very long.

Steffens: I have heard reports that when insulin reacts with some receptor sites the complex goes into the cell. Can this be a factor?

Porte: Possibly, but the turnover of those complexes in other tissues is relatively rapid. The best lead we've had comes from Dr. van Houten's [25] data providing evidence for internalization of insulin by brain cells. It's conceivable that the effect on feeding is modulated by this internalization process rather than by a membrane event on the surface of the cell.

Berthoud: In an animal like the obob mouse, which has a very high plasma insulin, it would seem to be contrary to your theory. Why doesn't the high insulin suppress feeding?

Porte: It's very easy to speculate and make hypotheses explaining various models of obesity. For example, perhaps the brain of the obob mouse is insensitive to insulin so more must be secreted. After all, these animals have peripheral insulin resistance. So the animal overeats until insulin gets high enough to curb the appetite, but by then the animal is obese.

Berthoud: Yes, but that theory could not explain the animal with a lesion of the ventromedial hypothalamus.

Porte: Presumably the lesion would destroy the animal's ability to respond to its insulin, so more would again be required. The animals then overeat and reregulate at a higher level. The problem is that there are many places where the weight-regulatory system can go wrong and cause obesity. All we can do at present is speculate.

Sclafani: The effect you see on body weight seems awfully small; i. e., a $500 \mathrm{~g}$. weight loss doesn't seem much for a $17 \mathrm{~kg}$ monkey. We can easily get changes of $500 \mathrm{mg}$ in rats starting at only $300 \mathrm{~g}$. How do you account for such a small effect?

Porte: Actually, the caloric loss induced in our experiments predicts exactly the loss of weight. It is a small effect relative to the percent changes which you see in rats, but it's constant and presumably can accumulate and become much larger over time.

Oomura: Have you performed electroencephalography in any of your experiments? Studies of Dr. Nicolaidis and others suggest that insulin added to the brain causes synchronization.

Nicolaidis: That's true, but that finding can not explain the long-term effect seen in these experiments. 